\title{
A GENERIC AGROHYDROLOGICAL MODEL WITH READILY AVAILABLE PARAMETERS FOR WATER MANAGEMENT IN CROP PRODUCTION
}

\author{
WU, F. Q. - LI, P. - WU, G. F. - ZHANG, K. F.* \\ Ningbo Institute of Technology, Zhejiang University, Ningbo 315100, China \\ (phone: +86-574-8813-0254; fax: +86-574-8813-0283) \\ *Corresponding author \\ e-mail:kfzhang@nit.zju.edu.cn \\ (Received $6^{\text {th }}$ Feb 2020; accepted $6^{\text {th }}$ May 2020)
}

\begin{abstract}
Agrohydrological models have increasingly become more and more powerful tools for precise agricultural water management. Although there are numerical models available, many of them are either oversimplified leading to unreliable results, or too complex and difficult to use. In this study, an agrohydrological model, which strikes a balance between the accuracy, complexity and generality, was first proposed by integrating a newly developed module for computing crop evapotranspiration using the dual crop coefficient approach by FAO56 into the widely employed HYDRUS-1D model. The proposed model was then validated and rigorously assessed again data from the field experiments of winter wheat grown in two contrasting soils. Results showed that the proposed model made good predictions for soil water content in various layers over the growing period. Also, it was revealed that the water initially contained in the subsoil accounted for about half of the total evapotranspired amount. The simulated proportions of root water uptake from each quarter of rooting depth coincided well with those from the previous studies under the condition of crops grown free from water stress. This indicates that the devised easy-to-use model had the potential to be utilised in studying soil-crop water relations.
\end{abstract}

Keywords: HYDRUS-1D, soil-crop system, soil water dynamics, evapotranspiration, agricultural water management

\section{Introduction}

Agriculture is the biggest water consumer in the world. It consumes about $70 \%$ world's accessible fresh water, and $60 \%$ of the applied water is wasted (Clay, 2004). It is, therefore, crucially important to manage precisely agricultural water use to save the world's most precious resource. With advances in soil and plant sciences and computer technology, more and more agrohydrological models, which accounts for the key processes governing the water cycle in the soil-crop system, have been developed, and are now playing an important role in agricultural water management (see reviews by Bastiaanssen et al. (2007) and more recently by Siad et al. (2019)).

In agrohydrological models, the algorithms of cascade type are often used for modeling soil water movement due to its simplicity (Burns, 1974; Arnold et al., 1993; Brisson et al., 1998; Droogers et al., 2001; Greenwood, 2001; Zhang et al., 2007, 2020; Renaud et al., 2008; Steduto et al., 2009; Rahn et al., 2010; Strati et al., 2018). Such models assume that downwards water flow only occurs when soil water content in a layer exceeds its field capacity and upwards flow is not allowed. The models use few parameters such as water content at saturation and field capacity and employ simple numerical algorithms. However, the determination of the flow coefficient in these models has proven problematic as it varies with time step, soil texture and other soil physical properties (Yang et al., 2009). As a result the flow coefficient often requires to be calibrated using a trial-and-error approach in advance. 
On the other hand, the numerical models using Richards' equation for soil water movement are more accurate, but more complex in predicting water dynamics in the soil-crop system. Enormous efforts have been made in developing agrohydrological models using the basic theory for soil water movement. Although great progress has been achieved (Bastiaanssen et al., 2007), the developed models use many parameters which are difficult to obtain, especially in the aspect of plant (Keating et al., 2003; Stöckle et al., 2003; Rahil and Antonopoulos, 2007). Dozens of parameters and complex algorithms describing crop physiology are normally involved in such as the EPIC models by Williams et al. (1993) and the DSSAT models by Jones et al. (2003). The models of this kind are often used in basic research or for specific crops, but are difficult to be applied universally and practically, resulting in low uptake of such models in crop production in agriculture (Bastiaanssen et al., 2007). Further, a review on agrohydrological models by Cannavo et al. (2008) revealed that a majority of models only dealt with a single crop.

Although numerious agrohydrological models have been proposed during the last decades, the importance of coupling hydrological and crop models for water use in crop management has been stressed in the recent review by Siad et al. (2019). A large body of literature show that such models have been further developed and widely applied for research and practical purposes. Bao et al. (2017) compared CSM-CERES-Maize and EPIC models for maize production, while Dokoohaki et al. (2016) developed a new version of CSM-CERES-Maize model by coupling SWAP and DSSAT package. Tribouillois et al. (2018) used AqYield model for predicting water balance of wheat and crop rotations. Autovinoa et al. (2018) employed Hydrus-2D model to study soil and plant water status dynamics in olive orchards under different irrigation systems.

It is clear from the above that agrohydrogical models have become powerful tools for agricultural water management. In spite of great efforts directed in developing agrohydrological models, there is still a clear need to devise models which strike the right balance between models' accuracy, complexity and generality. This is especially true for models to be used for the practical purpose where parameter values for sophisticated models are ofter unavailable.

In this study we aimed to develop and validate an agrohydrological model which uses the basic theory for soil water movement and relatively easily available parameters for crops. Since the HYDRUS-1D model (Šimunek et al., 2005) was well validated and widely used for simulating water movement and solute transport in agricultural soils (Shelia et al., 2017; Wang et al., 2017), it was chosen to form the framework of the agrohydrological model proposed in the study. The model was devised by combining the HYDRUS-1D model with a newly developed module for estimating potential evapotranspiration based on the dual crop coefficient approach by FAO56 (Allen et al., 1998) which could be used over a wide range of crops with readily available parameter values. Upon the completion of the model, the performance of the model was objectively evaluated again a widely used and commonly available dataset from the field experiments on winter wheat grown in two contrasting soils. 


\section{Materials and methods}

\section{Model description and evaluation}

\section{Model description}

The simulations in this study were carried out by using the HYDRUS-1D model integrated with the module for estimating potential crop transpiration and soil evaporation. As mentioned the above, HYDRUS-1D is a universal model simulating water movement and solute transport in porous media. Due to its nature of generality and well validated, the model has widely been applied successfully in a wide range of field. However, the model cannot be directly employed to simulate the dynamic process of water cycle in the soil-crop system during growth due to its inability of estimating evapotranspiration. In order to overcome the problem, we first developed a module for computing potential crop transpiration and soil evaporation based on the dual crop coefficient approach by the FAO56 (Allen et al., 1998), and then incorporated it into the HYDRUA-1D model. In the following we highlight the theory of developing such a module, while the detailed description of the HYDRUS-1D model can be seen elsewhere (Šimunek et al., 2005).

The potential crop transpiration and soil evaporation were calculated according to the dual crop efficient approach and estimated evapotranspiration by FAO56 (Allen et al., 1998). Both crop coefficients are dependent on crop species and its growth stages. Such an approach, simple though, has well validated over a wide range of crops under conditions of various climates and soils, and was employed by our previous studies (Yang et al., 2009; Zhang et al., 2009, 2010, 2020).

Daily potential evapotranspiration (Equation 1) is calculated by the Penman-Monteith equation (Allen et al., 1998):

$$
E T_{0}=\frac{0.408 \delta\left(R_{n}-G\right)+900 \gamma /(T+273) u_{2}\left(e_{s}-e_{a}\right)}{\delta+\gamma\left(1+0.34 u_{2}\right)}
$$

where $R_{n}\left(\mathrm{MJ} \mathrm{m}^{-2} \mathrm{~d}^{-1}\right)$ is the net radiation at the crop surface, $G\left(\mathrm{MJ} \mathrm{m}^{-2} \mathrm{~d}^{-1}\right)$ is the soil heat flux density, $u_{2}\left(\mathrm{~m} \mathrm{~s}^{-1}\right)$ is the $24 \mathrm{~h}$ average, wind speed at $2 \mathrm{~m}$ height, $e_{s}(\mathrm{kPa})$ is the saturation vapor pressure, $e_{a}(\mathrm{kPa})$ is the actual vapor pressure, $\delta\left(\mathrm{kPa}^{\circ} \mathrm{C}^{-1}\right)$ is the slope of the vapor pressure curve, $\gamma\left(\mathrm{kPa}^{\circ} \mathrm{C}^{-1}\right)$ is the psychrometric constant.

The calculated potential evapotranspiration ETo is partitioned into crop evaporation and soil evaporation using (Allen et al., 1998) (Equations 2 and 3):

$$
E T_{c}=T_{p o t}+E_{p o t}=\left(K_{c b}+K_{e}\right) E T_{0}
$$

in which:

$$
K_{e}=\min \left(K_{c \max }-K_{c b}, f K_{c \max }\right)
$$

where $T_{p o t}$ and $E_{p o t}$ are the potential transpiration and evaporation, respectively, $K_{c b}$ and $K_{e}$ are the basal crop coefficient for transpiration and the evaporation coefficient, respectively, $K_{\text {cmax }}$ is the maximum evapotranspiration coefficient, and $f$ is the soil fraction not covered by plants and exposed to evaporation. 
$K_{c b}$ increases with time at the crop development stage in a linear manner, and reaches its maximum and is stabilized in the middle growth stage when the ground is fully covered before it decreases with time towards crop maturity. $K_{e}$, however, changes in the opposite direction as $K_{c b}$. For the different crops, the values of both $K_{c b}$ and $K_{e}$ together with the definition of crop growth stages are given in Allen et al. (1998).

Figure 1 illustrates the calculation procedures in the agrohydrological outlined the above.

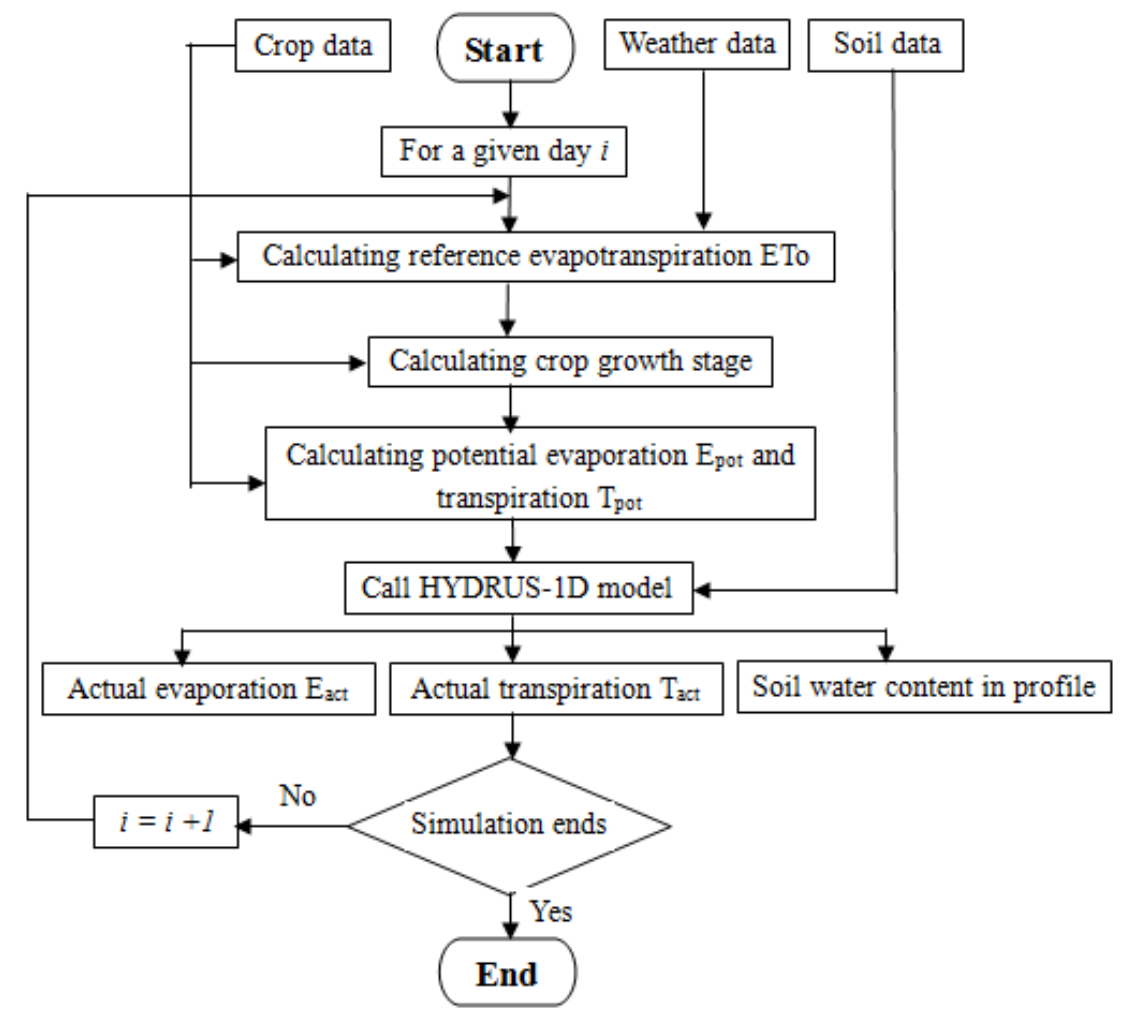

Figure 1. Flow chart of the proposed agrohydrological model for water dynamics

The biggest advantage of employing the dual crop coefficient approach by FAO56 (Allen et al., 1998) for estimating soil evaporation and crop transpiration was its generality. It could be applied with readily available parameter values for various crops. This approach was well validated and accepted worldwide and was successfully adopted in numerous agrohydrological models for calculating evapotranspiration (Zhang et al., 2010; Rahn et al., 2010).

\section{Model parameters}

Only few parameters are needed for running the model. Basically they are composed of three different types: soil data, crop data and weather data. The van Genuchten soil hydraulic properties (van Genuchten, 1980) describing the relations between soil water content, soil hydraulic conductivity and soil water potential in different soil layers are required. For the crop data they are the crop species, the dates of crop sowing/planting and harvest, the durations of various crop growth stages (initial, development, middle and late) and their corresponding values of dual crop coefficients $K_{c b}$ and $K_{e}$ according to 
FAO56 (Allen et al., 1998). The weather data include daily solar radiation, maximum and minimum air temperature, relative humidity, air speed and rainfall. The model can be run with the values of the above parameter together with soil boundary conditions and initial water content distribution in the soil profile.

\section{Model evaluation}

The model performance was assessed using the commonly adopted statistical indices of the Nash-Sutcliffe model efficiency coefficient (NSE) (Nash and Sutcliffe, 1970) (Equation 4), the root of the mean squared errors (RMSE) (Equation 5) and the mean error (ME) (Equation 6). Such an approach for assessing hydrological models was widely applied (Bohne and Salzmann, 2002; Yang et al., 2009; Zhang et al., 2020).

$$
\begin{aligned}
N S E & =1-\frac{\sum_{i=1}^{N}\left(Y-Y^{\prime}\right)^{2}}{\sum_{i=1}^{N}\left(Y-\overline{Y^{\prime}}\right)^{2}} \\
R M S E & =\sqrt{\frac{1}{N} \sum_{i=1}^{N}\left(Y-Y^{\prime}\right)^{2}} \\
M E & =\frac{1}{N} \sum_{i=1}^{N}\left(Y-Y^{\prime}\right)
\end{aligned}
$$

where $Y$ and $Y^{\prime}$ are the simulated and measured values, respectively, $N$ is the total number of measurements, and $\overline{Y^{\prime}}$ is the average of the measured values.

\section{Experiments}

The data from field experiments on winter wheat conducted at the Institute for Soil Fertility Research, The Netherlands from 1983 to 1984 (Groot and Verberne, 1991) was used to validate the model outlined the above. The measured dataset was comprehensive, and has been used extensively in previous studies to test agrohydrological models (De Willigen, 1991; Yang et al., 2009). A brief description of the experiments is given below, while the detailed description of the experiments can be found elsewhere (Groot and Verberne, 1991).

The experiments were conducted on two sites with contrasting soils: the Bouwing experiment (silty clay loam) and the PAGV experiment (silty loam) for the purpose of investigating the effects of both nitrogen and water on wheat growth. The crop was planted on 27 October, 1983, and harvested on 21 August, 1984. The total growth duation was 299 days. The duations of initial, development, middle and late growth stages were 37 days, 175 days, 50 days and 37 days, respectively. The soil physical properties in the 0-40 and 40-100 $\mathrm{cm}$ in the Bouwing farm, and in the 0-25, 25-40 and 40-100 $\mathrm{cm}$ in the PAGV farm were measured for determining soil hydraulic properties. The gravimetrical soil water content in the layers of $0-20,20-40,40-60,60-80$ and $80-100 \mathrm{~cm}$ were measured from soil cores taken in eight replicates at intervals of three weeks on 14 Feb., i.e. Day of Year 45 (DOY 45), 13 Mar. (DOY 73), 03 Apr. (DOY 94), 24 Apr. (DOY 
115), 08 May (DOY 129), 28 May (DOY 149), 19 Jun. (DOY 171), 03 Jul. (DOY 185), 17 Jul. (DOY 199), and 07 Aug. (DOY 220) in 1984 in each experiment. Also, the development of root growth was measured in the experiments, and the maximum rooting depth of $100 \mathrm{~cm}$ at harvest was measured. The measured weather variables included daily radiation, air temperature, relative humidity and rainfall. The measurments, taken at the Wageningen meteorological station located at a distance of $7 \mathrm{~km}$ from the Bouwing experiment and the Swifterbant meteorological station located at a distance of $15 \mathrm{~km}$ from the PAGV experiment, covered the entire crop growth period (Groot and Verberne, 1991).

\section{Preparation of model run}

\section{Model parameterization}

The model operated with a daily time step, with the data from soil, crop and weather as model inputs.

Soil data included the parameters describing the relationships of soil water content and hydraulic conductivity with soil water pressure head. The measurements for such relationships were carried out in the experiments (Groot and Verberne, 1991), but the measured parameters were not related in the way proposed by van Genuchten (1980). Since the model only used van Genuchten soil hydraulic parameters, the fitting procedure was implemented based on the measured layered datasets and the commonly available RETC software (van Genuchten, 1991). The fitted van Genuchten soil hydraulic properties for the various layers in both experiments are shown in Table 1 (after Yang et al., 2009).

Table 1. Fitted van Genuchten soil hydraulic parameter values using the RETC software (after Yang et al., 2009)

\begin{tabular}{c|c|c|c|c|c}
\hline & $0-40 \mathrm{~cm}$ & $40-100 \mathrm{~cm}$ & $0-25 \mathrm{~cm}$ & $25-40 \mathrm{~cm}$ & $40-100 \mathrm{~cm}$ \\
\hline$\theta_{\mathrm{s}}\left(\mathrm{cm}^{3} \mathrm{~cm}^{-3}\right)$ & 0.51 & 0.49 & 0.42 & 0.50 & 0.53 \\
$\theta_{\mathrm{r}}\left(\mathrm{cm}^{3} \mathrm{~cm}^{-3}\right)$ & 0.00 & 0.00 & 0.04 & 0.06 & 0.06 \\
$\alpha$ & 0.0266 & 0.0046 & 0.0162 & 0.0096 & 0.0098 \\
$n$ & 1.1841 & 1.1835 & 1.299 & 1.3460 & 1.3193 \\
$K_{\mathrm{S}}\left(\mathrm{cm} \mathrm{d}^{-1}\right)$ & 40.0 & 2.0 & 160.0 & 33.0 & 200.0 \\
\hline
\end{tabular}

Crop data used in the model were the dates of crop sowing and harvest, and the durations of various crop growth stages and their associated dual coefficients for soil evaporation and crop transpiration. The durations of the initial, development, middle and late crop growth stages was calculated according to the proportionalities over the entire growth period given in the FAO56 (Allen et al., 1998) for the studied crop. Also, the corresponding values of crop coefficients were taken from the FAO56. Thus, on any day during growth, the crop growth stage and the coefficients for evaporation and transpiration could be determined, given the reference evapotranspiration ETo (Equation 1) was known.

Weather data together with the geographical properties of the experimental plots were used for computing ETo. The weather data included daily air temperature, relative humidity, solar radiation, wind speed and rainfall. These items were all measured and used directly in the model run. 


\section{Computational domain and boundary conditions}

In both experiments, the calculated soil depth was $120 \mathrm{~cm}, 20 \mathrm{~cm}$ longer than the measured maximum rooting depth. The lower boundary in the Bouwing experiment was set as free drainage as there were layers of gravel at that depth, while in the PAGV experiment the lower boundary was specified as soil in saturation based on the experimental observations of the groundwater table (Groot and Verberne, 1991). These boundary conditions were identical as those used in the study by Yang et al. (2009). The date of the first measurements was used as the starting point, while the measured values of soil water content along the profile to the $120 \mathrm{~cm}$ depth were used as the initial conditions in the simulations.

\section{Results and discussion}

\section{Overall assessment of the model performance}

The statistical analyses between the simulated and measured values of soil water content at different depths collected during growth reveal that the model performed satisfactorily in simulating water dynamics for the studied cases (Table 2). The calculated values of RMSE and $M E$, both less than $0.05 \mathrm{~cm}^{3} \mathrm{~cm}^{-3}$, are all small, and the NSE values are relatively high. While the model over- and under-predicted slightly for the Bouwing and PAGV experiments (Table 2), respectively, no noticeable mean error was found in the overall comparison between simulation and measurement. This is also reflected in Figure 2 where the best fitted line is virtually overlapped the 1:1 line. Judged from Table 2 and Figure 2, it is reasonable to conclude that the simulated values of soil water content in various layers at various time intervals are in good agreement with the measurements, indicating the model is able to make good predictions.

Table 2. Statistical indices between the simulated and measured values of soil water content

\begin{tabular}{c|c|c|c}
\hline & $\begin{array}{c}\text { RMSE } \\
\left(\mathrm{cm}^{3} \mathrm{~cm}^{-3}\right)\end{array}$ & $\begin{array}{c}\text { ME } \\
\left(\mathrm{cm}^{3} \mathrm{~cm}^{-3}\right)\end{array}$ & $\begin{array}{c}\text { NSE } \\
(-)\end{array}$ \\
\hline Bouwing experiment & 0.033 & -0.012 & 0.586 \\
PAGV experiment & 0.043 & 0.010 & 0.550 \\
Both experiments & 0.038 & -0.001 & 0.634 \\
\hline
\end{tabular}

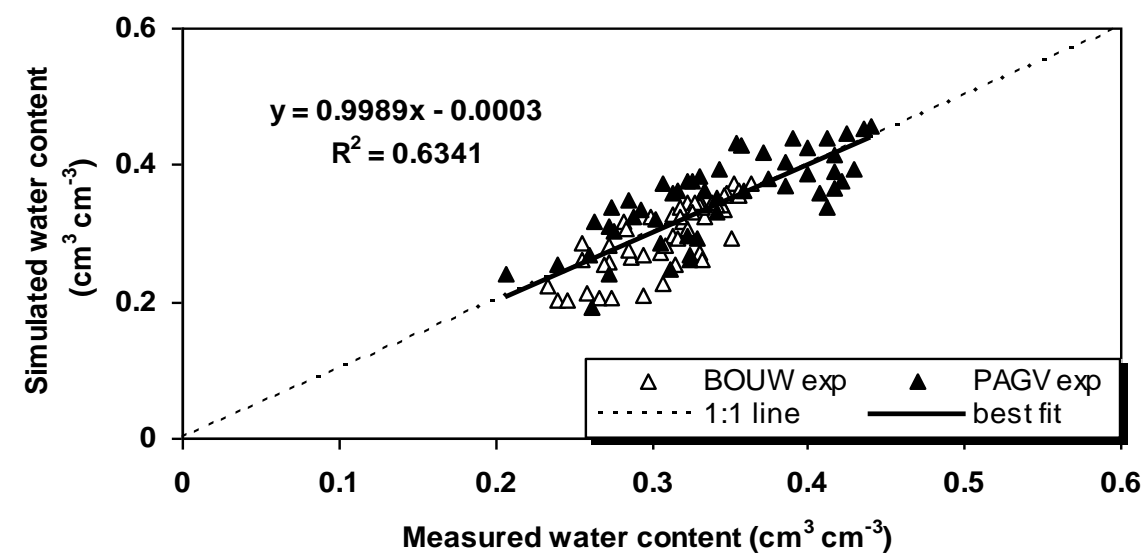

Figure 2. Comparison of soil water content between simulation and measurement in both experiments 


\section{Comparison of soil water content between simulation and measurement}

Detailed comparisons of soil water content over the entire simulation period in the different layers for both experiments are carried out, and Figure 3 shows some of such comparisons as an example. Expect for the layers of 20-40 cm where the noticeable discrepancies occur between simulation and measurement, all the other simulated values of soil water content agreed well with the measured values. Also it reveals that only in the top soil layer did the changes in soil water content correlate highly with rainfall, suggesting that the effect of rainfall mainly limited in the $20 \mathrm{~cm}$ depth. The discrepancies in the $20-40 \mathrm{~cm}$ layer might be due to the fact that this is the region where the boundary lies to separate the topsoil from the subsoil, and thus is difficult to determine soil hydraulic properties with accuracy (Yang et al., 2009). Overall Figure 3 confirms the results from statistical analyses shown previously that the model is capable of reproducing the results from the experiment.

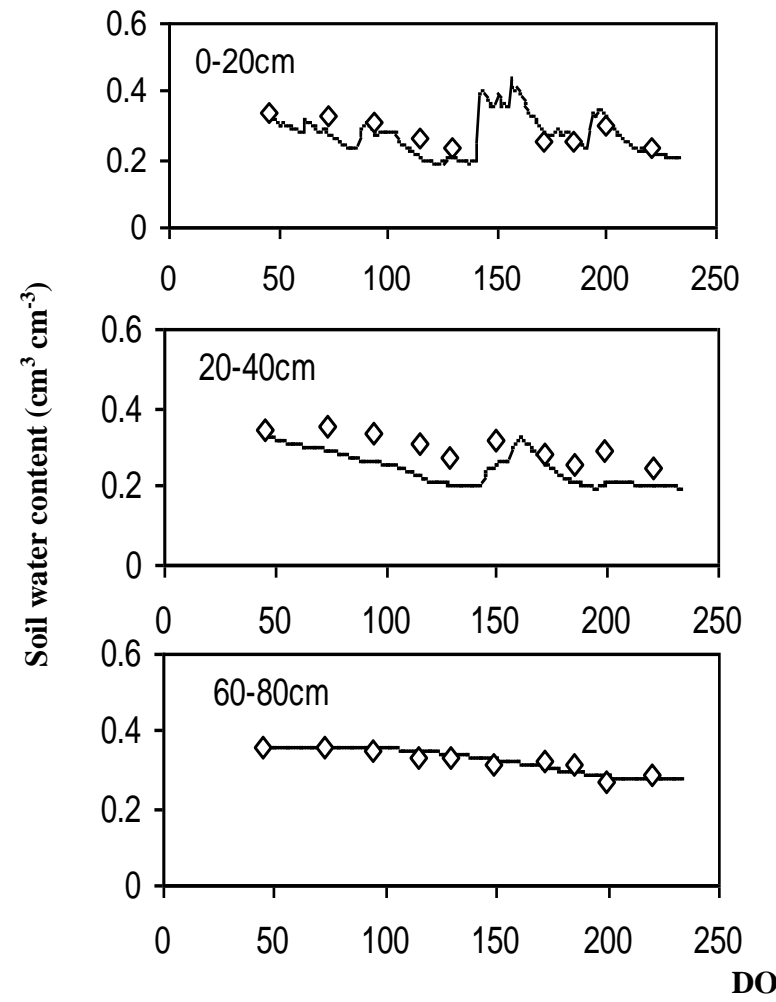

(a) Bouwing exp.
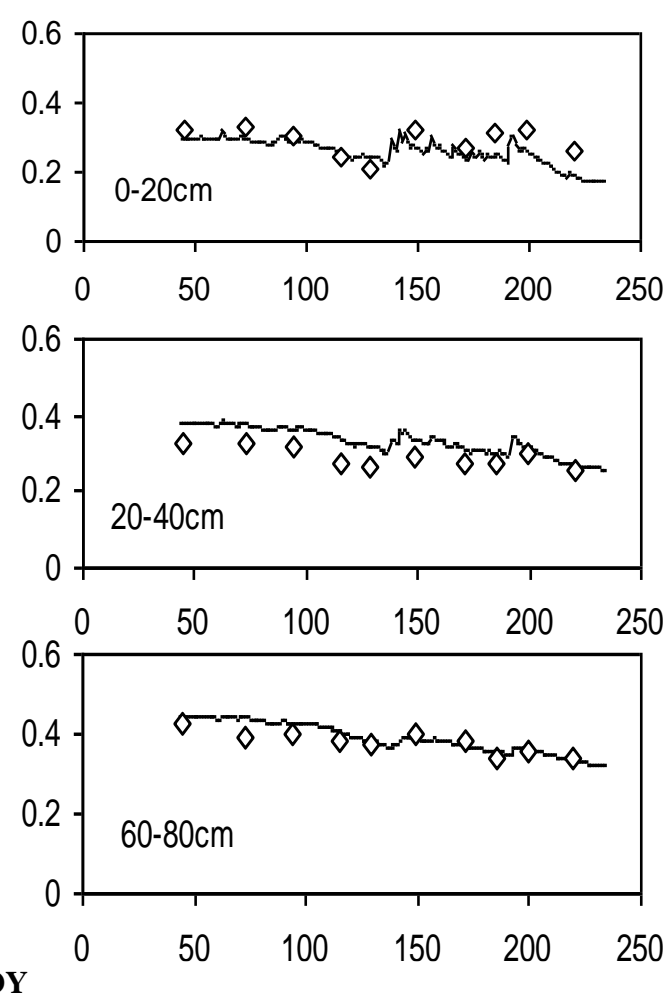

(b) PAGV exp.

Figure 3. Comparison between the measured and simulated volumetric soil water content at different soil layers in the Bouwing experiment (a) and in the PAGV experiment (b)

\section{Simulated soil evaporation and crop transpiration}

Soil evaporation and crop transpiration for the experiments were simulated and plotted in Figures 4 and 5. Clearly both the potential soil evaporation and crop transpiration estimated by the FAO56 were not met in the Bouwing experiment (Figure 4). During the periods of DOY 73-83, DOY 106-121 and after DOY 211, the simulated soil evaporation values were less than the potential ones. As for the crop transpiration, there were two periods of DOY 103-143 and DOY 180-234 when the simulated values were greatly 
smaller than the potential ones (Figure 4b). However, the situation in the PAGV experiment was rather opposite. Figure 5 demonstrates that only in a very small period towards the harvest when the simulated values of soil evaporation and crop transpiration did not achieve the potential values, the demanded crop evapotranspiration for the maximum growth was met, suggesting that the crop was not stressed induced by water deficit.

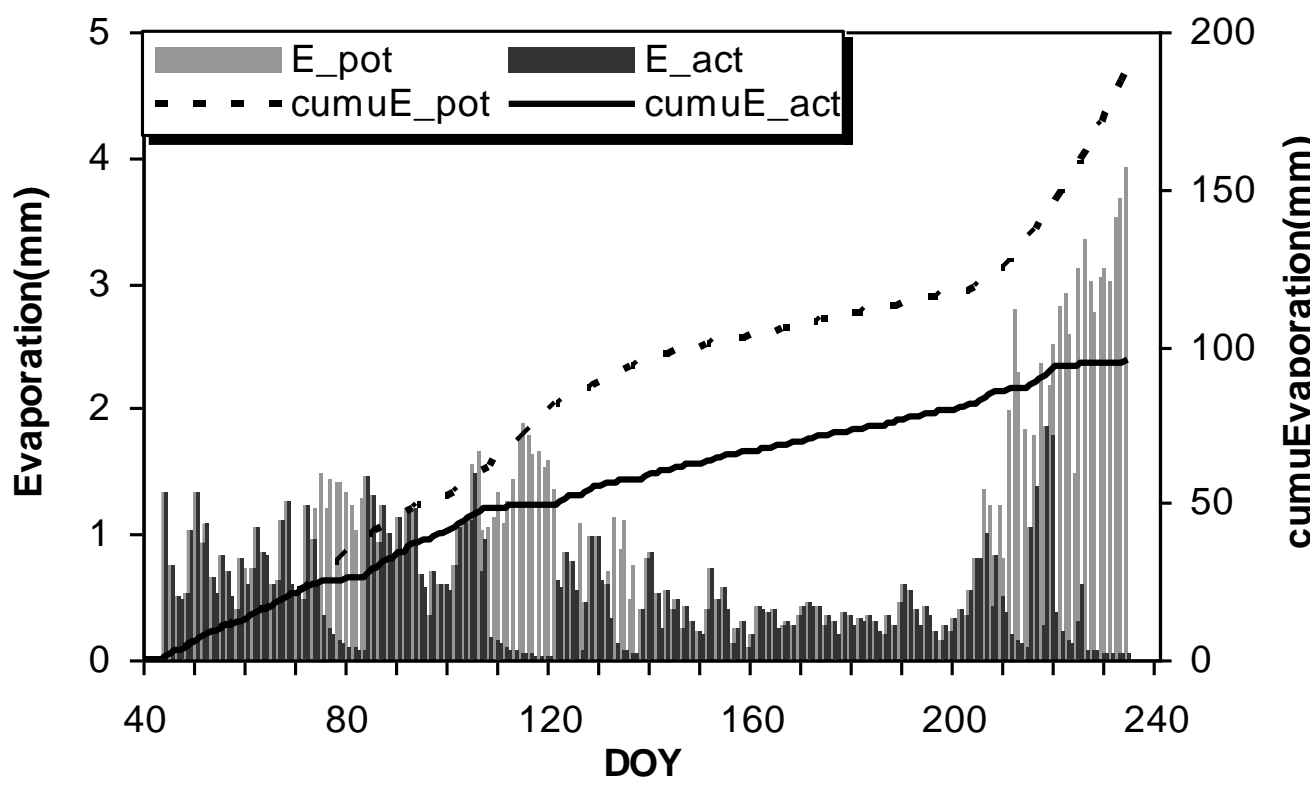

(a)

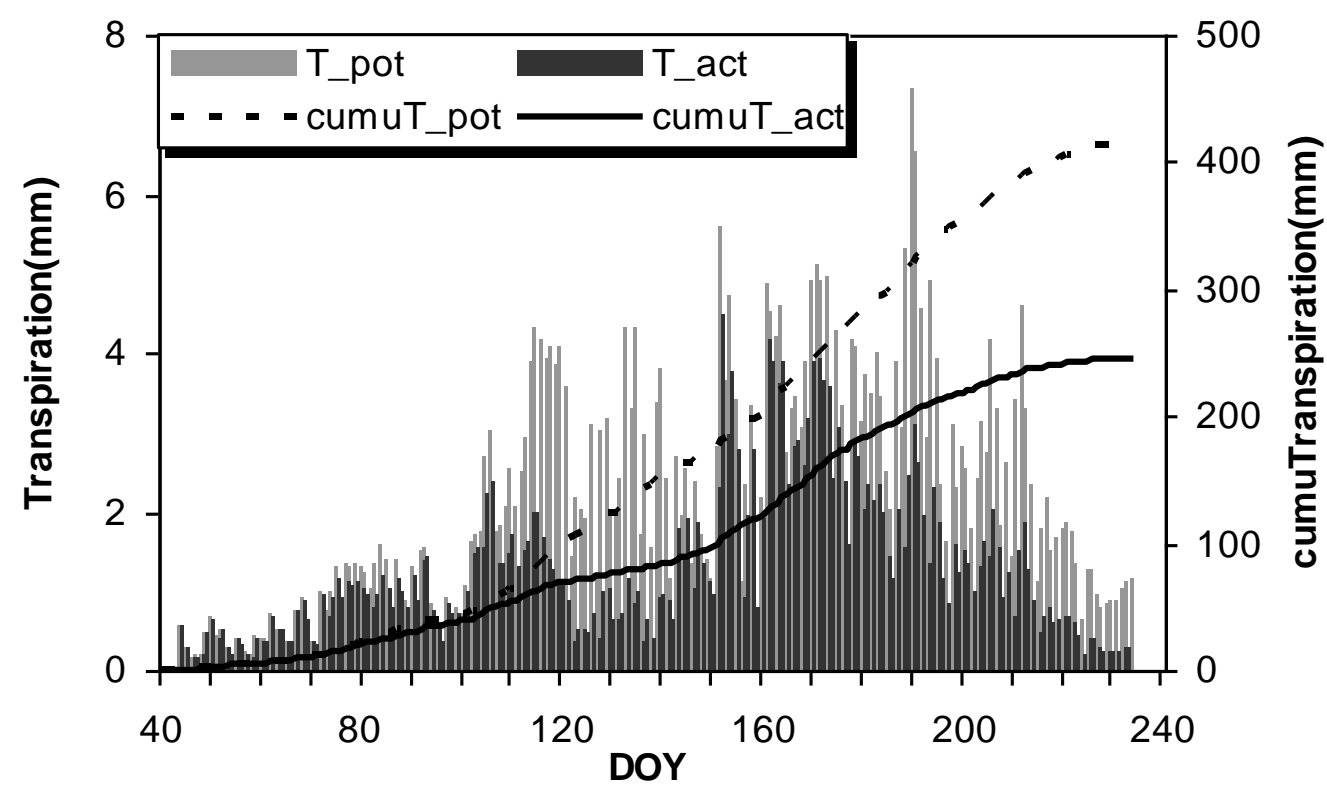

(b)

Figure 4. Simulated daily and cumulative potential and actual evaporation (a) and transpiration (b) in the Bouwing experiment 


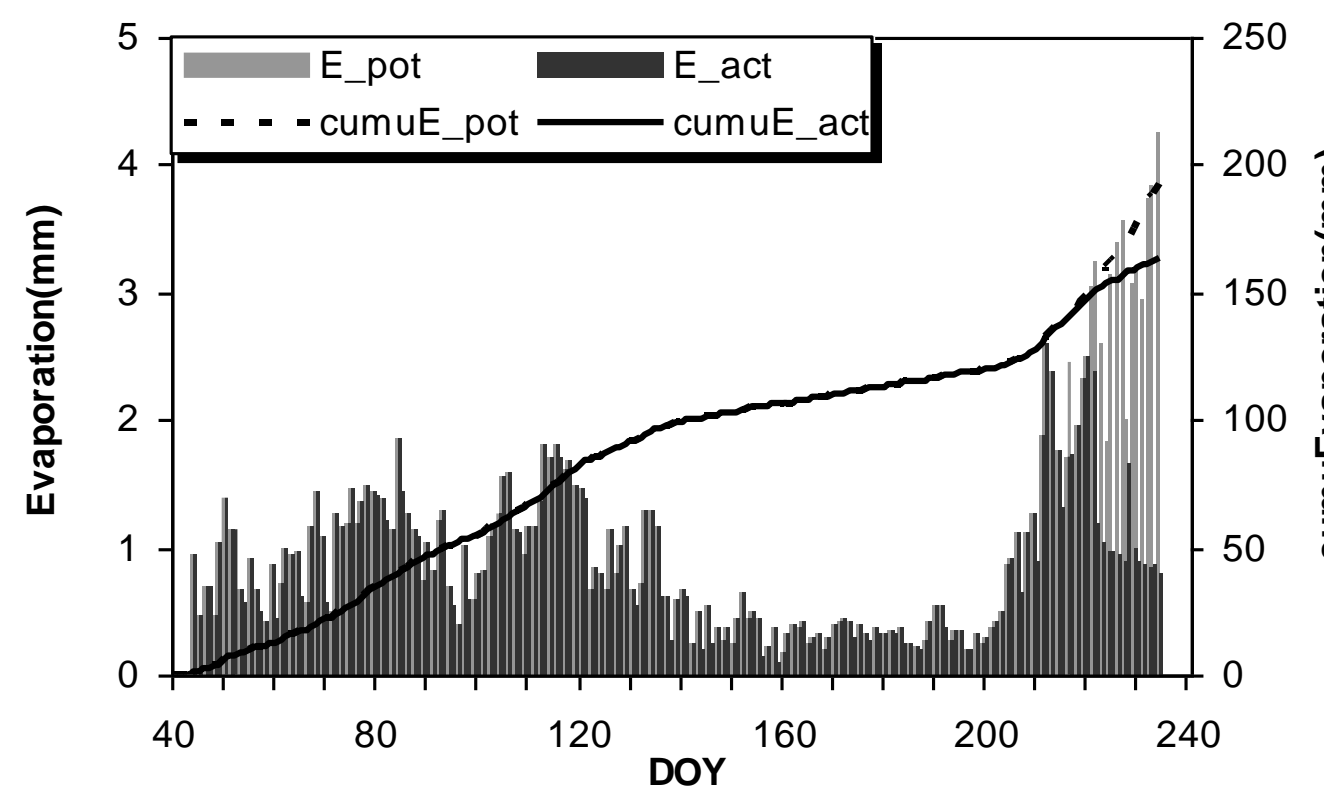

(a)

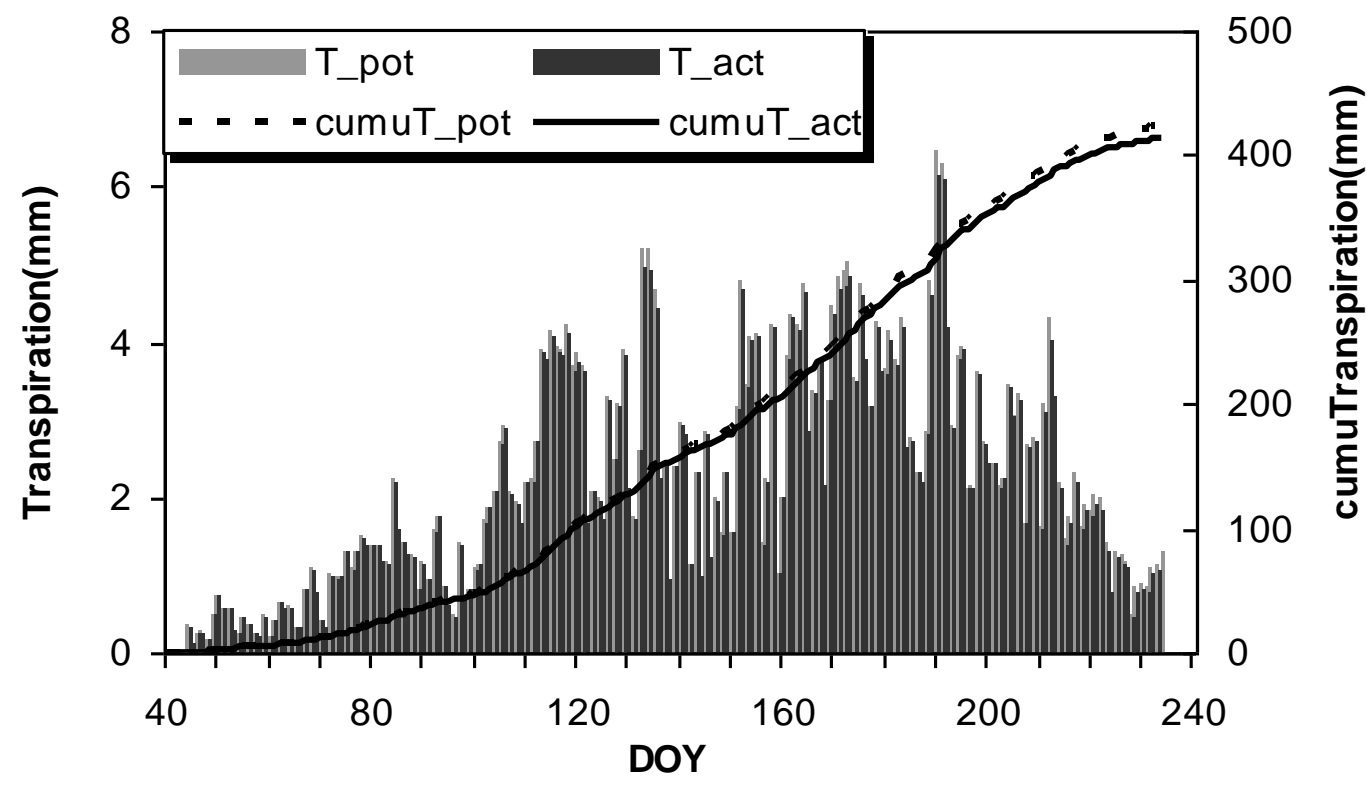

(b)

Figure 5. Simulated daily and cumulative potential and actual evaporation (a) and transpiration (b) in the PAGV experiment

\section{Water uptake from different portions of the rooting depth}

It is important to know the contribution of soil water in various part of the root zone to meet the crop demand for growth. Greenwood et al. (2010) argued that the subsoil could make a great contribution in meeting crop demand for water, while Molz and Remson (1970) and Kumar et al. (2013) estimated that each quarter of the rooting depth from the surface accounted for about $40 \%, 30 \%, 20 \%$ and $10 \%$ of the total water uptake. 
In the studied experiments the amounts of water uptake from different soil layers were calculated (Figure 6). During the first 50 days of the simulation period, the daily water uptake was small and mainly occurred in the top $20 \mathrm{~cm}$ layer due to the infancy of the crop. With the increase in time, roots gradually penetrated to the deeper soil and water uptake occurred in a wider region. 53.4\% and $44.9 \%$ of total water uptake were from the top $20 \mathrm{~cm}$ soil layer in the Bouwing and PAGV experiments, respectively. Since only a small amount of rainfall water reached the soil below $20 \mathrm{~cm}$ depth (Figure 3), it supports the argument by Greenwood et al. (2010) that water initially contained in the subsoil played an important role in meeting the crop demand for water. In the studied cases, approximately a half of the total tranpirated water was from the subsoil. Also, calculations show that in the Bouwing experiment, the proportions of the total water uptake from each quarter of the rooting depth were $48.3 \%, 25.3 \%, 16.9 \%$ and $9.5 \%$, respectively, while the corresponding values were $40.4 \%, 32.3 \%, 19.8 \%$ and $7.4 \%$ in the PAGV experiment. The simulated proportions in the PAGV experiment are in good agreement with the previous studies (Molz and Remson, 1970; Kumar et al., 2013). However, for the crop grown under the condition of water deficit such proportions of water uptake from the root zone might not be held, as shown in the Bouwing experiment.

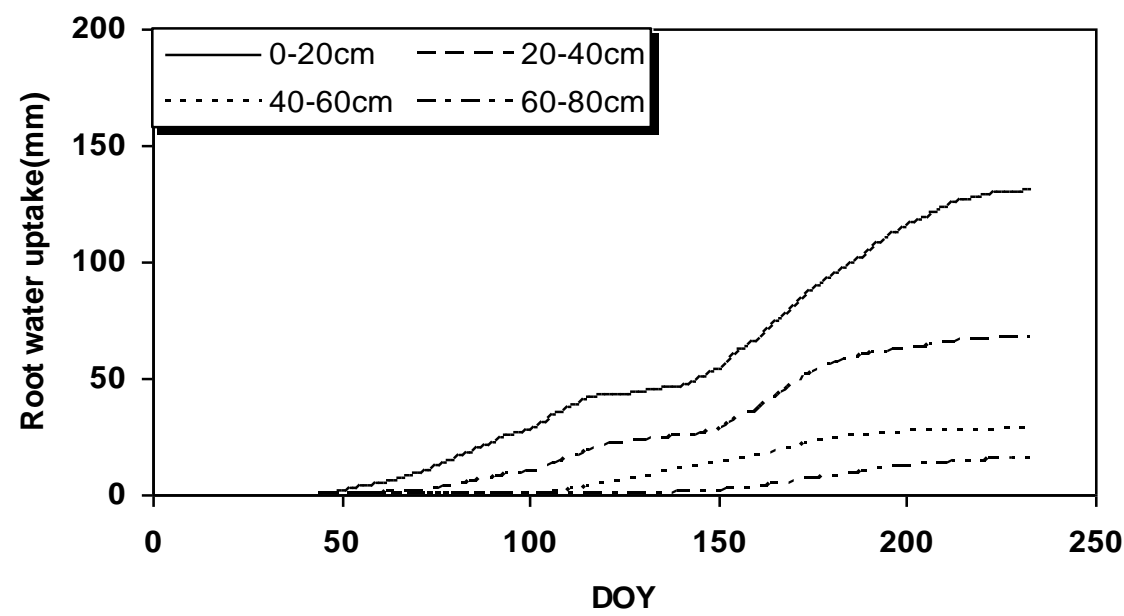

(a)

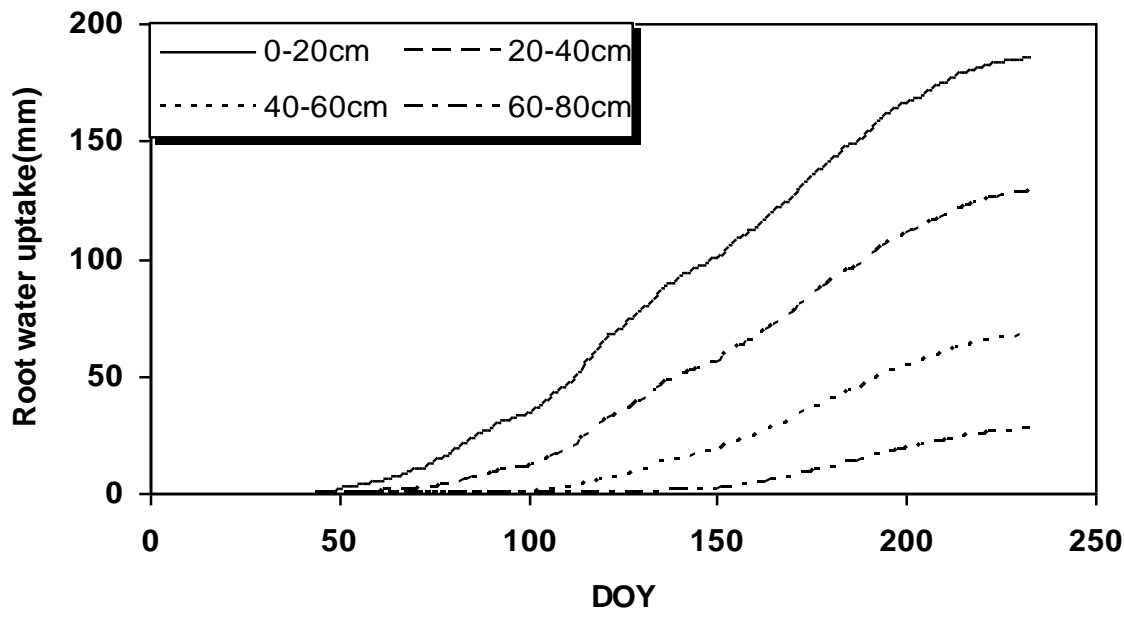

(b)

Figure 6. Simulated cumulative root water uptake in different soil layers in the Bouwing experiment ( $a$ ) and in the PAGV experiment (b) 


\section{Possible use of the proposed model}

As discussed the above, the proposed model performed well in predicting soil water dynamics in the soil-crop system for the studied cases. The model has the advantage of using easily available parameters, compared with most exsisting models which are more mechanistic, but are problematic in parameter determination., It is, therefore, that the model presented in this study has the potential to be applied more widely for the practical purpose.

Once it is validated extensively, it could be employed to study soil-crop water relations at the field scale or to form the core for devising model-based decision support systems for water mangement in a wide range of crop production. Also the model could be used for irrigation scheduling based on the predicted soil water status. Since soil water dynamics is an indespensible process in predicting soil nutrients availability, the model could further widen its application for crop nutrients management by extending its functions for simulating solute transport in soil and coupling it with crop models.

\section{Conclusions}

In this study an agrohydrological model was devised by integrating a module for estimating potential soil evaporation and crop transpiration into the HYDRUS-1D model. The model was easy to operate and could be applied universally with readily available parameters. Rigorous validation of the model revealed that the model was able to predict temporal and spatial soil water content in the soil-crop system. In the studied cases, the model produced fairly good predictions of soil water content during the growth of winter wheat in two contrasting soils and under different soil water regimes. The simulated results were not only in good agreement with the measurements, but also were supported by the findings from previous studies. This suggests that the development of the model was successful, and the proposed model could potentially be used in studying soil-crop water relations and in precise water use in agriculture.

Future work includes further validating the model against measured data on more crops and coupling the model with crop models for water and nutrients management. Efforts should also be made to investigate the effects of the uncertainty of model parameters on the predicted results of the model.

Acknowledgements. The authors wish to acknowledge the financial support from National Natural Science Foundation of China (51379187), National Natural Science Foundation of Zhejiang Province (LY17E090001), and Ningbo Science and Technology Bureau, China (2016C10057) for this study.

\section{REFERENCES}

[1] Allen, R. G., Pereira, L. S., Raes, D., Smith, M. (1998): Crop EvapotranspirationGuidelines for Computing Crop Water Requirements. - FAO, Irrigation and Drainage Paper No. 56. United Nations Food and Agriculture Organization, Rome, Italy.

[2] Arnold, J. G., Allen, P. M., Bernhardt, G. T. (1993): A comprehensive surface-ground water flow model. - Journal of Hydrology 142: 47-69.

[3] Autovinoa, D., Rallob, G., Provenzano, G. (2018): Predicting soil and plant water status dynamic in olive orchards under different irrigation systems with Hydrus-2D: Model performance and scenario analysis. - Agricultural Water Management 203: 225-235. 
[4] Bao, Y., Hoogenboom, G., McClendon, R., Vellidis, G. (2017): A comparison of the performance of the CSM-CERES-Maize and EPIC models using maize variety trial data. - Agricultural Systems 150: 109-119.

[5] Bastiaanssen, W. G. M., Allen, R. G., Droogers, P., D’Urso, G., Steduto, P. (2007): Twentyfive years modeling irrigated and drained soils: state of the art. - Agricultural Water Management 92: 111-125.

[6] Bohne, K., Salzmann, W. (2002): Inverse simulation of non-steady-state evaporation using nonequilibrium water retention data: a case study. - Geoderma 110: 49-62.

[7] Brisson, N., Mary, B., Ripoche, D., Jeuffroy, M. H., Ruget, F., Nicoullaud, B., Gate, P., Devienne-Barret, F., Antonioletti, R., Durr, C., Richard, G., Beaudoin, N., Recous, S., Tayot, X., Plenet, D., Cellier, P., Machet, J.-M., Meynard, J. M., Delécolle, R. (1998): STICS: a generic model for the simulation of crops and their water nitrogen balances. I. Theory and parameterization applied to wheat and corn. - Agronomie 18: 311-346.

[8] Burns, I. G. (1974): A model for predicting the redistribution of salts applied to fallow soils after excess rainfall or evaporation. - Journal of Soil Science 25: 165-178.

[9] Cannavo, P., Recous, S., Parnaudeau, V., Reau, R. (2008): Modelling N dynamics to assess environmental impacts of cropped soils. - Advances in Agronomy 97: 131-174.

[10] Clay, J. (2004): World Agriculture and the Environment: A Commodity-by-Commodity Guide to Impacts and Practices. - Washington, DC: Island Press.

[11] De Willigen, P. (1991): Nitrogen turnover in the soil-crop system; comparison of fourteen simulation models. - Fertilizer Research 27: 141-149.

[12] Dokoohaki, H., Gheysari, M., Mousavi, S. F., Zand-Parsa, S., Miguez, F. E., Archontoulis, S. V., Hoogenboom, G. (2016): Coupling and testing a new soil water module in DSSAT CERES-Maize model for maize production under semi-arid condition. - Agricultural Water Management 163: 90-99.

[13] Droogers, P., Tobari, M., Akbari, M., Pazira, E. (2001): Field-scale modeling to explore salinity problems in irrigated agriculture. - Irrigation and Drainage 50: 77-90.

[14] Greenwood, D. J. (2001): Modelling N-response of field vegetable crops grown under diverse conditions with N_ABLE: a review. - Journal of Plant Nutrition 24: 1799-1815.

[15] Greenwood, D. J., Zhang, K., Hilton, H., Thompson, A. (2010): Opportunities for improving irrigation efficiency with quantitative models, soil water sensors and wireless technology. - Journal of Agricultural Science 148: 1-16.

[16] Groot, J. J. R., Verberne, E. L. J. (1991): Response of wheat to nitrogen fertilization, a data set to validate simulation models for nitrogen dynamics in crop and soil. - Fertilizer Research 27: 349-383.

[17] Jones, J. W., Hoogenboom, G., Porter, C. H., Boote, K. J., Batchelor, W. D., Hunt, L. A., Wilkens, P. W., Singh, U., Gijsman, A. J., Ritchie, J. T. (2003): The DSSAT cropping system model. - European Journal of Agronomy 18: 235-265.

[18] Keating, B. A., Carberry, P. S., Hammer, G. L., Probert, M. E., Robertson, M. J. (2003): An overview of APSIM, a model designed for farming systems simulation. - European Journal of Agronomy 18: 235-266.

[19] Kumar, R., Jat, M. K., Shankar, V. (2013): Evaluation of modeling of water ecohydrologic dynamics in soil-root system. - Ecological Modelling 269: 51-60.

[20] Molz, F. J., Remson, L. (1970): Extraction term models of water soil moisture use by transpiring plants. - Water Resources Research 6(5): 1346-1356.

[21] Nash, J. E., Sutcliffe, J. V. (1970): River flow forecasting through conceptual models part 1-a discussion of principles. - Journal of Hydrology 10: 282-290.

[22] Rahil, M. H., Antonopoulos, V. Z. (2007): Simulating soil water flow and nitrogen dynamics in a sunflower field irrigated with reclaimed wastewater. - Agricultural Water Management 92: 142-150.

[23] Rahn, C. R., Zhang, K., Lillywhite, R., Ramos, C., Doltra, J., de Paz, J. M., Riley, H., Fink, M., Nendel, C., Thorup-Kristensen, K., Pedersen, A., Piro, F., Venezia, A., Firth, C., Schmutz, U., Rayns, F., Strohmeyer, K. (2010): EU-Rotate_N - a decision support system 
- to predict environment and economic consequences of the management of nitrogen fertilizer in crop rotations. - European Journal of Horticultural Science 75(1): 20-32.

[24] Renaud, F. G., Bellamy, P. H., Brown, C. D. (2008): Simulation pesticides in ditches to asses ecological risk (SPIDER): I. Model description. - The Science of Total Environment 394: 112-123.

[25] Shelia, V., Šimunek, J., Boote, K., Hoogenboom, G. (2017): Coupled the DSSAT abd hydrus-1D for soil water dynamics simulation in the soil-plant-atmosphere system. - ASA, CSSA and SSSA International Annual Meetings 2016.

[26] Siad, S. M., Iacobellis, V., Zdruli, P., Gioia, A., Stavi, I., Hoogenboom, G. (2019): A review of coupled hydrologic and crop growth models. - Agricultural Water Management 224: 105746.

[27] Šimunek, J., van Genuchten, M. Th., Šejna, M. (2005): The HYDRUS-1D software package for simulating the movement of water, heat, and multiple solutes in variably saturated media. - University of California-Riverside, Research Report 3: 1-240.

[28] Steduto, P., Hsiao, T. C., Raes, D., Fereres, E. (2009): Aquacrop-the fao crop model to simulate yield response to water: I. Concepts and underlying principles. - Agronomy Journal 101: 426-437.

[29] Stöckle, C. O., Donatelli, M., Nelson, R. (2003): CropSyst, a cropping systems simulation model. - European Journal of Agronomy 18: 289-308.

[30] Strati, V., Albéri, M., Anconelli, S., Baldoncini, M., Bittelli, M., Bottardi, C., Chiarelli, E., Fabbri, B., Guidi, V., Raptis, K. G. C., Solimando, D., Tomei, F., Villani, G., Mantovani, F. (2018): Modelling Soil Water Content in a Tomato Field: Proximal Gamma Ray Spectroscopy and Soil-Crop System Models. - Agriculture 8: 60. doi:10.3390/agriculture8040060.

[31] Tribouillois, H., Constantin, J., Willaume, M., Brut, A., Ceschia, E., Tallec, T., Beaudoin, N., Therond, O. (2018): Predicting water balance of wheat and crop rotations with a simple model: AqYield. - Agricultural and Forest Meteorology 262: 412-422.

[32] van Genuchten, M. Th. (1980): A closed-form equation for predicting the hydraulic conductivity of unsaturated soils. - Soil Science Society of America Journal 44: 892-898.

[33] van Genuchten, M. Th., Leij, F. J., Yates, S. R. (1991): The RETC code for quantifying the hydraulic functions of unsaturated soils. - Robert S. Kerr Environmental Research Laboratory, US Environmental Protection Agency, Oklahoma, USA.

[34] Wang, X., Liu, G., Yang, J., Huang, G., Yao, R. (2017): Evaluating the effects of irrigation water salinity on water movement, crop yield and water use efficiency by means of a coupled hydrologic/crop growth model. - Agricultural Water Management 185: 13-26.

[35] Williams, J. R., Jones, C. A., Dyke, P. T. (1993): The Epic model. - In: Sharpley, A. N., Williams, J. R. (eds.) Epic-Erosion Productivity Impact Calculator. 1. Model documentation. U S Department of Agriculture Technical Bulletin No 1768. USDA: Washington DC.

[36] Yang, D., Zhang, T., Zhang, K., Greenwood, D. J., Hammond, J., White, P. J. (2009): An easily implemented agro-hydrological procedure with dynamic root simulation for water transfer in the crop-soil system: validation and application. - Journal of Hydrology 370: 177-190.

[37] Zhang, K., Greenwood, D. J., White, P. J., Burns, I. G. (2007): A dynamic model for the combined effects of $\mathrm{N}, \mathrm{P}$ and $\mathrm{K}$ fertilizers on yield and mineral composition: description and experimental test. - Plant and Soil 298: 81-98.

[38] Zhang, K., Yang, D., Greenwood, D. J., Rahn, C. R., Thorup-Kristenseen, K. (2009): Development and critical evaluation of a generic 2-D agro-hydrological model (SMCR_N) for the responses of crop yield and nitrogen composition to nitrogen fertilizer. - Agriculture Ecosystems and Environment 132: 160-172.

[39] Zhang, K., Greenwood, D. J., Spracklen, W. P., Rahn, C. R., Hammond, J. P., White, P. J., Burns, I. G. (2010): A universal agro-hydrological model for water and nitrogen cycles in 
the soil-crop system SMCR_N: Critical update and further validation. - Agricultural Water Management 97: 1411-1422.

[40] Zhang, K., Li, C., Hu, Z., Huang, S., Chen, J., Ma, X. (2020): Simulations of water cycle in the soil-crop system: model improvement and validation. - Applied Ecology and Environmental Research 18: 2163-2177. 